\title{
IMMUNODIAGNOSTICS OF CEREBRAL TOXOPLASMOSIS DEPENDING ON PERMEABILITY OF BLOOD-BRAIN BARRIER
}

DOI: 10.36740/WLek202002114

\author{
Andriy V. Bondarenko, Dmitro V. Katsapov, Anatoliy V. Gavrylov, Tatiana V. Didova, Ivan A. Nahornyi \\ DEPARTMENT OF INFECTIOUS DISEASES, NATIONAL MEDICAL UNIVERSITY, KHARKIV, UKRAINE
}

\begin{abstract}
The aim of the work was to detect a diagnostic value of CNSToxolndex - index of correlation between albumin concentration and anti-toxoplasma antibodies, which reflects local production of anti-toxoplasma lgG in CNS compared with their level in blood.

Materials and methods: 30 HIV-infected persons with the IV clinical stage (16 man and 14 women) aged from 25 to 49 years with clinical and instrumental signs of cerebral toxoplasmosis were selected from the general array of the patients treated in the Regional Clinical Infectious Hospital. A retrospective parallel detection of IgG T. gondii was performed in serum and CSF in patients, whose results of ELISA or PCR on T. gondii were positive. Blood serum and CSF were obtained from patients at the same time. All samples for analysis were stored at $-20^{\circ} \mathrm{C}$ and then tested on the RT-2100C Rayto Life and Analytical Sciences Co., Ltd (China) immunoassay analyser for quantitative detection of the level of specific anti-Toxicoplasma lgG. Detection of albumin concentration in serum and CSF was performed on the Chemray-120 Automated Biochemical Analyzer Rayto Life and Analytical Sciences Co., Ltd (China) using the Liquick Cor-ALBUMIN Diagnostic Kit.

Results: Specific IgG to T. gondii in blood plasma was found in 27 patients (90\%) while in CSF only in 7 (23\%). The results of the research in this group of patients were represented by the following parameters: patient 1 (blood antiToxo lg $-200 \mathrm{IU} / \mathrm{ml}$, blood albumin - $36 \mathrm{~g} / \mathrm{l}$, CSF antiToxo lg G - 10 IU/ml, CSF albumin - 0.8 g/l, CNSToxolndex - 2.3); patient 2 (150 / 40 / 90 / 0.7 / 34.3, respectively); patient 3 (90/35 / 64 / 0.25 / 99.6); patient 4 (140/39/10/0.19/ 14.7); patient 5 (88 / 52 / 48 / 0.21 / 135.1$)$; patient 6 (160 / 48 / 50 / 0.15 / 100.0); patient 7 (122 / 42 / 15 / 0.17 / 30.4). Consequently, taking into consideration the diagnostic marker CNSToxolndex more than 10.0, cerebral toxoplasmosis was diagnosed only in six patients from seven, in whom anti-toxoplasma antibodies in (SF were detected. Patient 1, despite clinical symptoms similar to cerebral toxoplasmosis, and substitute signs of cerebral toxoplasmosis detected with the help of neuroimaging methods (volumetric formation of the right frontal lobe with a ring-shaped enhancement), availability of specific anti-toxoplasma antibodies in blood serum and CSF, diagnosis of cerebral toxoplasmosis has not been confirmed. M. tuberculosis DNA was found in CSF by PCR. Conclusions: CNSToxoIndex allows evaluating the local production of anti-toxoplasmic lgG in CNS and their diffusion from blood as a result of the blood-brain barrier damage and it is a powerful method of cerebral toxoplasmosis diagnostics in HIV-positive people as well.
\end{abstract}

KEY WORDS: cerebral toxoplasmosis, HIV-infection, blood-brain barrier, CNSToxoIndex, immunodiagnostics

Wiad Lek. 2020;73(2):285-288

\section{INTRODUCTION}

Toxoplasmosis is the most common protozoa infection in the whole world. A high risk of cerebral toxoplasmosis occurs in individuals with the level of CD4 lymphocytes less than 100 cells $/ \mu \mathrm{L}$. Therefore, cerebral toxoplasmosis is one of the most common causes of focal brain lesions in immunocompromised patients, such as those with human immunodeficiency virus (HIV). There is a six-fold increase risk in the chances of developing encephalitis as a result of reactivation of persistent toxoplasmosis than as a result of a primary infection of seronegative individuals in HIV-infection [1].

The diagnosis of cerebral toxoplasmosis in HIV-infected individuals is based on the following: 1) clinical symptoms with a tendency to progression which makes it possible to suspect toxoplasmosis: disturbance of consciousness, fever, seizures, headache, focal neurological symptoms (lethargy, craniocerebral paralysis and paresis, motor disorders, impaired coordination of movements, loss of visual fields, aphasia); 2) using neuroimaging techniques (detection one or more ring-shaped centres); 3 ) detection of the microorganism in a clinical specimen (histological examination of brain tissues or detection of DNA by polymerase chain reaction); 4) evaluation of the effectiveness of trial etiotropic treatment [2].

However, the clinical symptoms of cerebral toxoplasmosis in HIV-infected patients are not specific and require a differential diagnosis with primary lymphoma, progressive multifocal leukoencephalopathy, tuberculosis (including tuberculoma), bacterial brain abscess, cytomegalovirus and herpes simplex encephalitis, cryprococcosis or mycobacteriosis [3].

Computed tomography (CT) or magnetic resonance imaging (MRI) gives presumptive diagnosis of cerebral toxoplasmosis. A computerized axial tomography scan is a sensitive diagnostic method for focal neurological deficits, but it may not diagnose the minimal inflammatory response seen in early stages. Magnetic resonance imaging is more sensitive than the computed tomography scan in diagnosing toxoplasmosis from brain lesions. The findings are observed in cerebral toxoplasmosis as hypodense lesions with a ring enhancing and perilesional oedema, which are seen in the 
majority of patients. Nevertheless, in $20 \%$ of patients, hypodense lesions are without contrast enhancing and focal lesions may be absent. Furthermore, the same ring accumulation of contrast is described in tuberculomas. Newer imaging techniques such as signal photon emission CT or positron emission CT can enhance the specificity to rule out other CNS lesions such as lymphoma, but their use is extremely limited [8]. Moreover, the development of disseminated encephalitis without signs of a focus lesion is possible in cerebral toxoplasmosis, which always ends lethally [2].

A needle stereotactic biopsy under the control of CT (which is not performed in most hospitals) is required for cytological detection of Toxoplasma gondii ( $T$. gondii) in cerebral tissues. Furthermore, a brain biopsy is recommended only in case of absence of a clinical or radiological response to a specific therapy, delaying an appointment of etiotropic therapy. Alternative methods are detection of specific antibodies by the enzyme-linked immunosorbent assay (ELISA) or pathogen's DNA by polymerase chain reaction (PCR) [4].

In the current clinical protocol, the diagnosis of toxoplasmosis is minimized. It is enough to detect an IgG antibody titter in blood serum to diagnose toxoplasmosis in HIV-infected people [5]. Diagnosis of toxoplasmosis is unlikely in the absence of serum specific IgG antibodies. The incident of toxoplasmosis in patients without antibodies to T. gondii in serum is very low. However, taking into account the fact that T. gondii infects most of the inhabitants (up to $70 \%$ of the population of Ukraine), the presence in blood of a specific IgG is an unreliable diagnostic criterion. Against the background of expressed immunodeficiency, the synthesis of anti-toxoplasma IgM and IgA is reduced, so they are generally absent in the manifestation of a chronic stage of toxoplasmosis. The quantitative method of the antibody titter detection is devoid of a diagnostic value, as well as the antibody avidity test, since the obligatory condition for the development of cerebral toxoplasmosis is the reactivation of the process [6].

A low diagnostic value of PCR for the detection of the genetic material in blood and cerebrospinal fluid (CSF) is related to the intracellular location of T. gondii, a small number of lesions and their distances from the CSF paths. The fact that a certain part of the DNA gets into CSF does not guarantee its long delay due to the local activity of the deoxyribonuclease. The detection of T. gondii by PCR in CSF is characterized by high specificity $(96-100 \%)$ but low sensitivity $(<50 \%)$ [2].

If significant confirmations of toxoplasmic aetiology have not been received, a trial treatment with anti-toxoplasma drugs for 2 weeks is used. However, the argument for ex juvantibus therapy is not very convincing, since such treatment is quite toxic and is accompanied by irreversible loss of time in the presence of other pathology. There is a known method for diagnosing cerebral toxoplasmosis by ELISA and western blot of CSF samples in comparison with clinical, serological and radiological data, especially in countries with high latent toxoplasmosis among the general population [7].

\section{THE AIM}

The main goal of the work is to determine the diagnostic value of the ToxoCNSIndex, which is calculated as the ratio between albumin concentration and T. gondii IgG in blood and CSF.

\section{MATERIALS AND METHODS}

HIV-infected patients with symptoms of CNS involvement, undergoing treatment in Regional Clinical Infectious Hospital, were under observation. The clinical examination was aimed at finding out the details of the anamnesis of life and illness. The lifestyle of the patient (their sexual behaviour, use of psychotropic substances, alcohol) was taken into account in the epidemiological history. During the review, attention was drawn to the state of increased nervous activity, psycho-emotional sphere, as well as to the detection of meningeal and cerebral symptoms. In patients with impaired consciousness, establishment of cerebral oedema neurological signs were important. The study of cranial nerves functions, motor, sensitive and coordinating spheres, autonomic and vascular systems were performed.

30 HIV-infected persons with the IV clinical stage (16 men and 14 women) in the age group of 25-49 years were selected from the total number of patients with the signs of cerebral toxoplasmosis. General clinical trials have been performed: diagnostic lumbar puncture, CT and / or MRI of the brain, bacterioscopy of CSF for the presence of Mycobacterium tuberculosis and Cryptococcus neoformans, ELISA for IgM and IgG to HSV $1 / 2$, VZV, EBV, CMV, $M$. tuberculosis, T. gondii, as well as PCR of CSF to detect the DNA of these pathogens.

A retrospective parallel detection of IgG T. gondii was performed in serum and CSF in patients, whose results of ELISA or PCR on T. gondii were positive. The VektoToxo-IgG test system was used for this purpose. It is a set of reagents for immune enzyme detection of IgG to T. gondii in the serum. Blood serum and CSF were obtained from patients at the same time. All samples for analysis were stored at $-20^{\circ} \mathrm{C}$ and then tested on the RT-2100C Rayto Life and Analytical Sciences Co., Ltd (China) immunoassay analyser for quantitative detection of the level of specific anti-Toxicoplasma IgG. The method for detection of specific IgG antibodies was based on a two-stage solid-phase enzyme-linked immunosorbent assay using T. gondii antigen and monoclonal antibodies against human IgG. At the first stage of the assay, the test and control blood samples and CSF were incubated in wells with an immobilized antigen of T. gondii. Serum specific antibodies to T. gondii bind to the antigen to form the "antigen-antibody" complex. At the second stage, the antibody compound interacts with the conjugate of monoclonal antibodies against human IgG with horseradish peroxidase. The "antigen-antibody-conjugate" complex was shown to be color-coded using a peroxidase substrate - hydrogen peroxide and chromogentetramethylbenzidine. Optical density of the solutions was measured in the wells at $450 \mathrm{~nm}$ wavelength after adding a stop reagent (the reference filter is in the range $620-655 \mathrm{~nm}$ ). 
Table I. Results of the research of patients.

\begin{tabular}{|c|c|c|c|c|c|}
\hline \multirow[b]{2}{*}{ Patient } & \multicolumn{2}{|c|}{ Blood } & \multicolumn{2}{|c|}{ CSF } & \multirow{2}{*}{$\begin{array}{l}\text { CNSToxo } \\
\text { Index }\end{array}$} \\
\hline & $\begin{array}{c}\text { Level of IgG, } \\
\text { IU/ml }\end{array}$ & $\begin{array}{l}\text { Level of albumin, } \\
\mathrm{g} / \mathrm{l}\end{array}$ & $\begin{array}{c}\text { Level of IgG, } \\
\text { IU/mI }\end{array}$ & $\begin{array}{c}\text { Level of albumin, } \\
\text { g/l }\end{array}$ & \\
\hline №1 & 200 & 36 & 10 & 0,8 & 2,3 \\
\hline №2 & 150 & 40 & 90 & 0,7 & 34,3 \\
\hline №3 & 90 & 35 & 64 & 0,25 & 99,6 \\
\hline №4 & 140 & 39 & 10 & 0,19 & 14,7 \\
\hline №5 & 88 & 52 & 48 & 0,21 & 135,1 \\
\hline №6 & 160 & 48 & 50 & 0,15 & 100,0 \\
\hline №7 & 122 & 42 & 15 & 0,17 & 30,4 \\
\hline
\end{tabular}

The intensity of the colour was proportional to the number of IgG bound to T. gondii.

Detection of albumin concentration in serum and CSF was performed on the Chemray-120 Automated Biochemical Analyzer Rayto Life and Analytical Sciences Co., Ltd (China) using the Liquick Cor-ALBUMIN Diagnostic Kit. The method for determining the albumin was based on the formation of a coloured complex with bromocresol green in the succinate buffer, followed by measuring the absorption of the formed complex at a wavelength of $630 \mathrm{~nm}$, which is directly proportional to the albumin concentration in the sample being studied.

The procedure was strictly done in compliance with the Declaration of Helsinki after approval from the Regional Ethical Review Board at Kharkiv National Medical University.

\section{RESULTS AND DISCUSSION}

The clinical picture of the investigated HIV-infected individuals did not differ in specificity and required the differential diagnosis with other neuroinfections. In 13 (43.3\%) patients who were examined by MRI, there were focal lesions of the brain with signs typical to toxoplasmosis: one or more necrotic lesions in the form of a ring in the substance of the brain, cortex or basal ganglia. However, the same ring accumulation of contrast is described in tuberculomas of the brain [10].

Specific IgG to T. gondii in plasma was found in 27 patients $(90 \%)$. In all patients with a positive result of ELISA in the blood, specific antitoxicoplasmic IgG were detected in fairly high concentrations and with avidity of more than $40 \%$, indicating the presence of a chronic infection. In the analysis of CSF specific IgG to T. gondii was found in only 7 (23\%) patients. In all the patients in which IgG to $T$. gondii were present in CSF, IgG to T. gondii were also detected in blood serum. This indicates the impossibility of the isolated appearance of specific antibodies in CSF in the absence of them in the blood. In patients with IgG to T. gondii only in serum during diagnosis and treatment, no definitive diagnosis of CT was found.

The obtained data on the amount of IgG to T. gondii that persisted in the blood and intrathecal showed that specific antibodies in CSF were found to be lower in concentrations than in serum in each patient. This is most likely due to a lower number of pathogens in the nerve tissue than in internal organs.

There is no ultimate correspondence of antibodies growth in the blood and CSF, which gives grounds (in the case of their detection CSF) to talk about their intrathecal production. However, antibodies can diffuse in CSF from blood in case of the blood-brain barrier damage, which occurs in cerebral toxoplasmosis.

A way to improve the accuracy of cerebral toxoplasmosis diagnosis in HIV-infected individuals may be to identify the concentration of albumin and specific anti-toxoplasma IgG simultaneously in CSF and serum with the calculation of CNSToxoIndex index, which was developed by us:

\section{CNSToxoIndex $=\frac{\text { CSF antiToxo } I g G \times \text { blood albumin }}{\text { blood antiToxo IgG } \times \text { CSF albumin }}$}

where CSF antiToxo IgG - specific anti-toxoplasma antibodies in CSF (IU/ml), blood antiToxo IgG - specific anti-toxoplasma antibodies in blood serum (IU/ml), CSF albumin - albumin concentration in CSF (g/l), blood albumin - albumin concentration in serum of blood $(\mathrm{g} / \mathrm{l})$.

Results of the research in this group of patients were represented in the table I.

Simultaneous consideration of the results of the blood serum test and CSF allows comparing the concentrations of IgG to T. gondii, such as those that persist in blood, and localized in the nerve tissue. Assuming the possibility of penetration of antibodies from blood in CSF in case of the blood-brain barrier damage, take into account the ratio of antibody titres, taking into account the ratio of albumin concentration in these compartments. Albumin forms the foundation of CSF protein, but it is almost not synthesized in CNS and predominantly penetrates the bloodstream. Increasing the level of albumin in CSF is an indicator of the blood-brain barrier damage [11].

With CNSToxoIndex more than 10.0, the presence of specific anti-toxoplasmic IgG antibodies in CSF is mainly due to intrathecal synthesis and not to diffusion from blood, which is a diagnostic marker of cerebral toxoplasmosis.

The effectiveness of the method is proved by the following clinical examples: 
Patient 1: MRI: signs of volumetric formation of the right frontal lobe with signs of ring-shaped strengthening. In the clinical analysis of blood: hypochromic anaemia, leucocyte formula within the normal range, an increase in the rate of erythrocyte sedimentation up to $44 \mathrm{~mm} / \mathrm{h}$. CSF: colourless, clear, protein $-1.4 \mathrm{~g} / \mathrm{l}$, number of cells $-954 \times 10^{6} / \mathrm{l}$, lymphocytes $-80 \%$, glucose $-0.6 \mathrm{mmol} / \mathrm{l}$, chlorides -108 mmol/l. CSF PCR: HSV-2 DNA, EBV, CMV and T. gondii were not detected, $M$. tuberculosis DNA was detected.

Serum levels of IgG to T. gondii were detected at $200 \mathrm{IU} /$ $\mathrm{ml}$, and in CSF - $10 \mathrm{IU} / \mathrm{ml}$. The albumin of blood serum was $36 \mathrm{~g} / \mathrm{l}$, and CSF - $0.8 \mathrm{~g} / \mathrm{l}$. CNSToxoIndex was 2.3, indicating the diffusion of antibodies from blood, which is due to the blood-brain barrier damage.

After anti-tuberculosis treatment, the general condition of the patient improved. The headache was kept for 14 days, meningeal signs - during the 21st and fever - within 25 days. Sanitation of CSF was observed on day 26 of the disease. On day 27, the patient was discharged from hospital with a final diagnosis: HIV infection, IV clinical stage. Tuberculous meningoencephalitis. Cerebral oedema.

Patient 2: MRI: signs of multifocal encephalitis with a predominant lesion of the cerebellum; a moderate external asymmetric internal hydrocephalus. The clinical analysis of blood: hypochromic anaemia, nuclear neutrophilic shift to the right (shift index - 0.03) at the normal level of leukocytes. In cerebrospinal fluid: colourless, clear, protein -1.2 $\mathrm{g} / \mathrm{l}$, number of cells $-5.0 \times 10^{6} / \mathrm{l}$, lymphocytes $-100 \%$, glucose - $3.0 \mathrm{mmol} / \mathrm{l}$, chlorides $-118 \mathrm{mmol} / \mathrm{l}$. CSF PCR: HSV-2 DNA, EBV, CMV, M. tuberculosis and T. gondii were not found.

Serum levels of IgG to T. gondii were detected at $150 \mathrm{IU} / \mathrm{ml}$, and in CSF $-90 \mathrm{IU} / \mathrm{ml}$. Albumin of blood serum was $40 \mathrm{~g} / \mathrm{l}$, and CSF - $0.7 \mathrm{~g} / \mathrm{l}$. CNSToxoIndex was 34.3 , which is a diagnostic marker for the presence of intrathecal antibody production.

After anti-toxoplasma therapy, the patient's general condition was improved. A headache remained for ten days, meningeal signs and fever - within four days. On the 16th day of the illness, the patient was discharged from the hospital with the final diagnosis: HIV infection, IV clinical stage. Cerebral toxoplasmosis. Multifocal encephalitis.

\section{CONCLUSIONS}

CNSToxoIndex allows evaluating the local production of anti-toxoplasmic IgG in CNS and their diffusion from blood as a result of the blood-brain barrier damage and it is a powerful method of cerebral toxoplasmosis diagnostics in HIV-positive people as well.

\section{REFERENCES}

1. Hryzhak IH. The risk of toxoplasmic encephalitis in HIV-infected patients with different serological profiles of antitoxoplasma antibodies. ScienceRise: Medical Science. 2016; 7(3): 9-14.

2. Ostashko SI, Chibisova IV, Avaliani N, Azarskova MV, Andrianova IV, Antoniak SM, et al. Prevention, diagnosis and treatment of opportunistic infections and concomitant diseases in HIV-infected persons: Clinical Invention based on evidence (project). 20017. $470 \mathrm{p}$.
3. Hryzhak IH. Laboratory diagnostics of cerebral toxoplasmosis. Infectious Diseases. 2014; 1; 46-49.

4. Vidal JE, Diaz AV, de Oliveira AC, Dauar RF, Colombo FA, Pereira-Chioccola VL. Importance of high $\operatorname{lgG}$ anti-Toxoplasma gondii titers and PCR detection of T. gondii DNA in peripheral blood samples for the diagnosis of AIDS-related cerebral toxoplasmosis: a case-control study. Braz J Infect Dis. 2011; 15(4): 356-9.

5. Guidelines for the diagnosis and treatment of opportunistic infections and common symptoms in HIV-infected adults and adolescents № 182. Kyiv, 2007. $45 \mathrm{p}$.

6. Lipkovska L.V. Clinical and laboratory description of the acute stage of purchased toxoplasmosis. Infectious Diseases. 2013; 3; 64-69.

7. Meira CS, Vidal JE, Costa-Silva TA, Frazatti-Gallina N, Pereira-Chioccola VL. Immunodiagnosis in cerebrospinal fluid of cerebral toxoplasmosis and HIV-infected patients using Toxoplasma gondii excreted/secreted antigens. Diagn Microbiol Infect Dis. 2011; 71(3): 279-85.

8. Basavaraju A. Toxoplasmosis in HIV infection: An overview. Trop Parasitol. 2016; 6(2): 129-135.

9. Hryzhak IH, Dykyi BM, Pryshliak OYa, Prokofiev MZ, inventors; Ivano-Frankivsk National Medical University, patent holder. Method of differential diagnosis of cerebral toxoplasmosis in HIV-infected individuals. Patent of Ukraine UA 109701. 2015.09. 25.

10. Smith AB, Smirniotopoulos JG, Rushing EJ. Central Nervous System Infections Associated with Human Immunodeficiency Virus Infection: Radiologic Pathologic Correlation. Radio Graphics. 2008; 28: 2033-2058.

11. LeVine SM. Albumin and multiple sclerosis. BMC Neurology. 2016; 16: 47.

\section{ORCID and contributionship:}

Andriy V. Bondarenko - 0000-0002-2303-8525

Dmytro V. Katsapov - 0000-0001-9581-2009C

Anatoliy V. Gavrylov - 0000-0003-3926-3396

Tatiana V. Didova - 0000-0001-9844-2015 ${ }^{B}$

Ivan A. Nahornyi - 0000-0002-8202-5652

\section{Conflicts of interest:}

Authors declare no conflict of interest.

\section{CORRESPONDING AUTHOR \\ Andriy V. Bondarenko}

Department of Infectious Diseases,

Kharkiv National Medical University

Avenue Nauki 4, Kharkiv, 61022, Ukraine

tel: +380505310684

e-mail:avbond@ukr.net

Received: 27.05 .2019

Accepted: 29.11.2019

A - Work concept and design, B - Data collection and analysis, C - Responsibility for statistical analysis,

D-Writing the article, $\mathbf{E}$-Critical review, $\mathbf{F}-$ Final approval of the article 